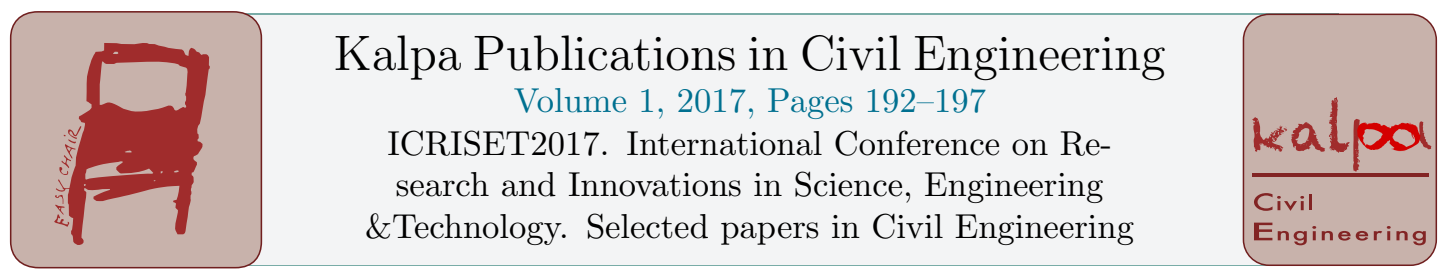

\title{
FE Analysis of Curved Castellated Girder for Variable Thermal Condition
}

\author{
Saurabh Pandya ${ }^{1}$, Prof. Mazhar Dhankot ${ }^{2}$ \\ ${ }^{1}$ PG Research Scholar, Department of civil engineering, Marwadi Education Foundation's Group of \\ Institutions, Rajkot, Gujarat, India \\ shppandya@gmail.com \\ ${ }^{2}$ Associate Professor, Department of civil engineering, Marwadi Education Foundation's Group of \\ Institutions, Rajkot, Gujarat, India \\ mazhar.dhankot@marwadieducation.edu.in
}

\begin{abstract}
Castellated girders having straight or curved profile are extensively used in structural application due to its aesthetics, versatility, economy and ease of use. The present paper is focused on Finite Element Analysis of curved castellated steel beam. The prime objective is to study the impact of opening and rise on behaviour of these curved steel beams. A parametric study has been conducted on arched castellated girder for various ratio of depth to opening for variable degree of curvature proportional to the span of the girder. The main focus of study in this paper is the temperature variation that exists between building interior and external environment. The FEA study reveals from the results that mid span deflection of beam increases with increase in size of opening. It is also observed that there is a sudden reduction of stresses when the span to rise ratio is reduced from 7 to 6 .
\end{abstract}

Keywords - Curved castellated beam; Circular web opening; Finite Element Analysis, Variable Temperature effect.

\section{Introduction}

Curved castellated steel beams combine aesthetics, versatility and economy in steel design. These are fabricated from standard rolled section \& are engineered to save time of construction, enabling saving in steel and reducing building cost. Many attempts have been made by structural engineers to find a way to decrease the cost of steel structures. Due to limitation on maximum allowable deflection, the high strength properties of structural steel cannot always be utilized to best advantages. As a result several new methods have been developed aiming at increasing the stiffness of steel 
members without any increasing in weight of the steel required. Beam with web opening is one of these solutions. Curved castellated beams are used in commercial buildings, industrial buildings and warehouses as roof beams [8]. The buildings generally nowadays are equipped with air conditioners that results into a variable temperature during the entire day. This variation is more critical in countries like India, where the difference in outside and inside temperature can go as high as 30 Degree Celsius. The variable temperature in a curved profile result in generation of stresses which needs to be accounted during the design process. To study the effect of these variables temperature in a castellated girder with curved profile needs attention. An effort has been made in this paper to derive stresses at these variable temperatures for different sizes of opening and degree of curvature. The degree of curvature in the current study has been provided in conjunction with the span of the girder.

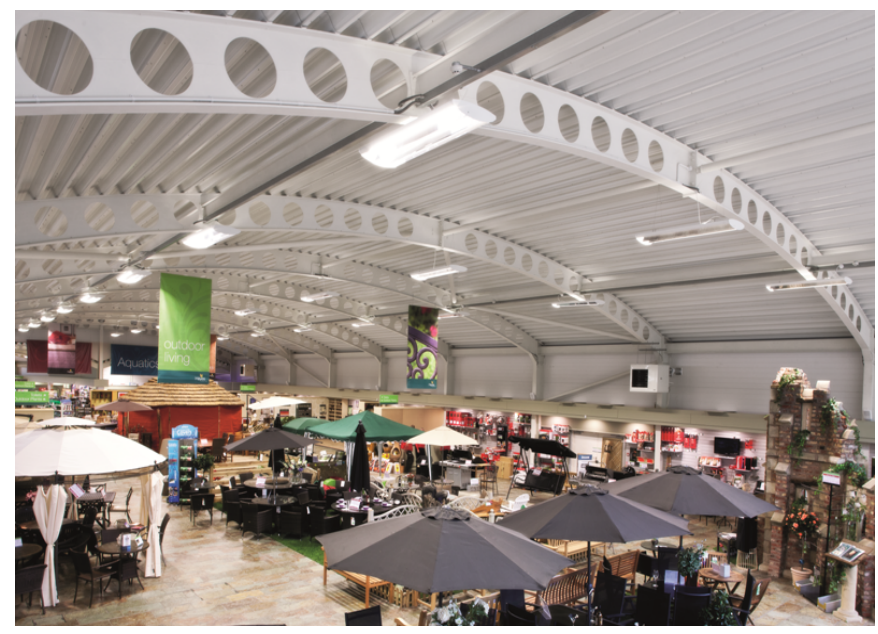

Figure 1 Curved castellated beam in public building (IMAGE SOURCE: http://www.steelconstruction.info)

A lot of research has been undertaken to understand the behaviour of castellated girder in normal circumstances. S. Morkhade, L. Gupta has stated that circular web opening are effective as compared to openings with other shapes. And it is also reported that spacing to diameter ratio of 1.5 is effective Error! Reference source not found.. G. veríssimo, R. facury, J. ribeiro reported that opening located at neutral zone of beam do not reduce strength of beam Error! Reference source not found.. The structural penalty on the load carrying capacity of steel beams due to the presence of web openings may be completely eliminated through rational design of the web openings in terms of the locations along beam span and also the opening sizes. This was demonstrated by K.F. Chung, T.C.H. Liu, A.C.H. Ko [5]. Y. L. Pi, M. A. Bradford proposed design equation for the in-plane strength of steel arches in uniform compression Error! Reference source not found.

\section{Numerical study}

For current study, the opening provided in the castellated girder is of circular shape. A parametric study is conducted by varying the diameter of the opening in conjunction with depth of the girder and varying the degree of curvature in conjunction with the span. Total deflection and equivalent stress are the parameters which have been compared for all the variations. The support condition in the steel structures plays a very important role in evaluating stresses in the members. This study has been undertaken for hinged and fixed conditions which is highly analogous to the actual support conditions possible on site. 
FE analysis has been conducted for ISMB 400 under various conditions of opening diameter and span to depth ratio. The curved beam is analysed as fixed beam and two hinged under uniformly distributed load. The temperature differences are created at faces of beam and deflection and equivalent stresses are compared. Beam with opening is made from same ISMB 400 beam taking diameter of opening as $0.5,0.6$ and 0.7 times the depth of the beam. Spacing to diameter ratio is taken as 1.5. The degree of curvature is also varied by changing the span to rise ratio of the circular curve. The span to rise ratio is varied from 10 to 5 at an interval of 1 . The above span to rise ratio has not been reduced beyond five considered taking into account the difficulty in generating the curve profile.

ISMB 400 is considered in the study under uniformly distributed load of $3 \mathrm{kN} / \mathrm{m}$. Load is applied based on wind load, dead load, and live load combination. For Wind load it is considered structure is located at Rajkot, where wind velocity is $39 \mathrm{~m} / \mathrm{s}$. Factors $\mathrm{K}_{1}$ is taken $1, \mathrm{~K}_{2}$ taken as 1 for terrain category 2 and building class-B, $\mathrm{K}_{3}$ are taken as 1 suggested by IS: 875 - Part-3. Dead load of roofing material is taken as $0.15 \mathrm{kN} / \mathrm{m}^{2}$ as per IS: $875-$ Part- 2 .

Difference in standard room temperature and environment temperature is taken as $0^{\circ}, 10^{\circ}, 20^{\circ}, 30^{\circ}$. For this room temperature is considered to be $20^{\circ} \mathrm{C}$ and environment temperature is raised from $20^{\circ} \mathrm{C}$ to $50^{\circ} \mathrm{C}$ at interval of $10^{\circ} \mathrm{C}$.

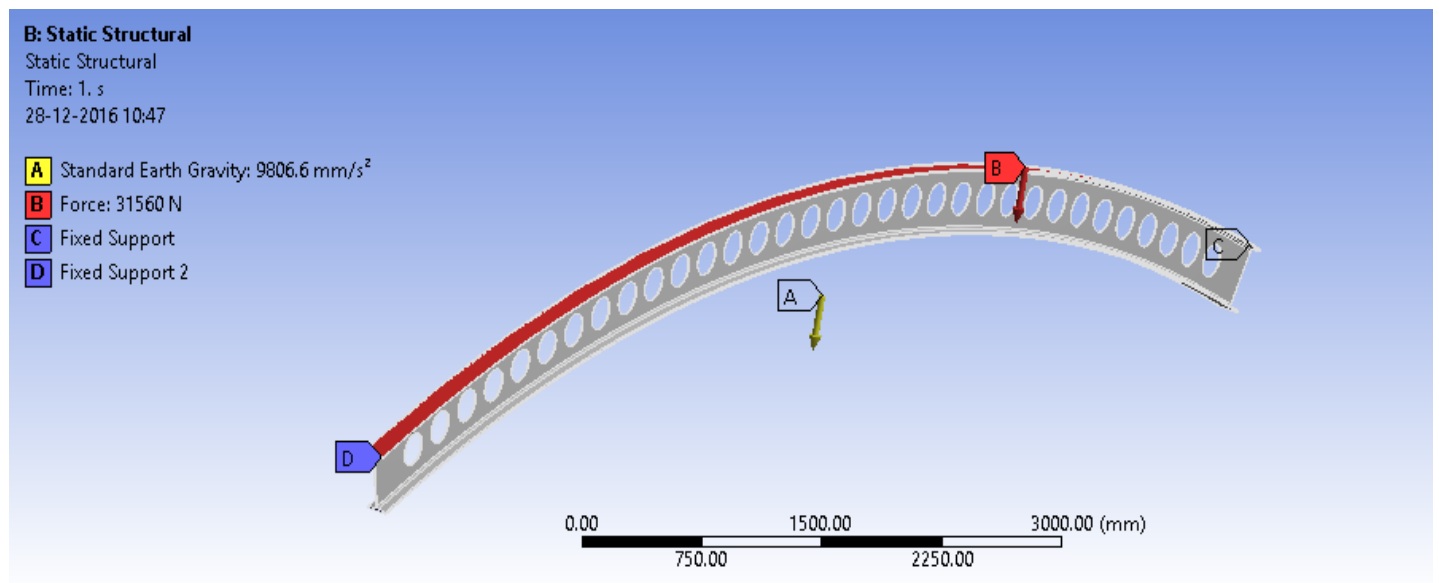

Figure 2 Loading on curved beam

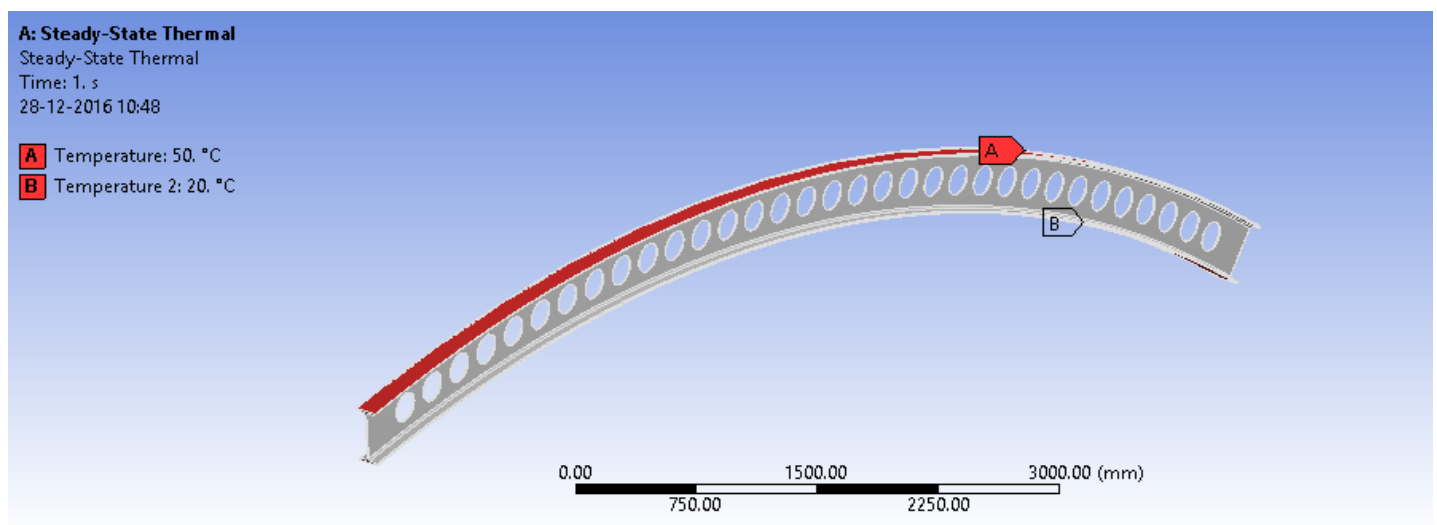

Figure 3 Thermal loading on curved beam 


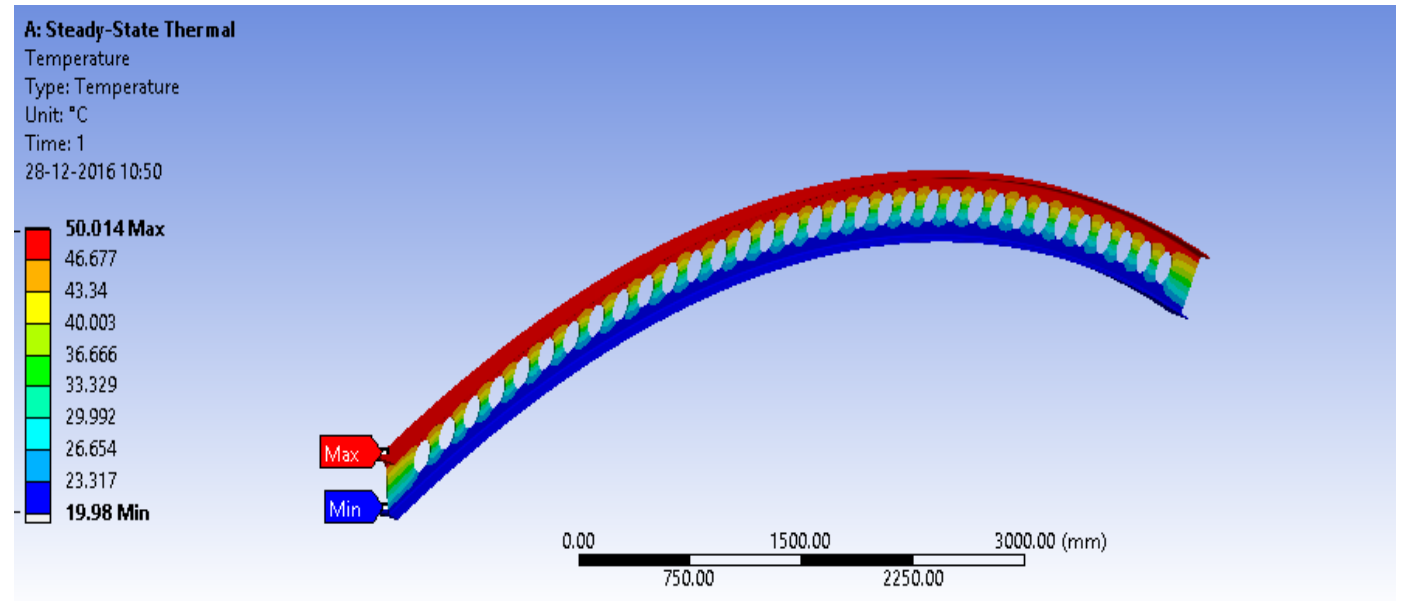

Figure 4 Temperature distribution along curved beam
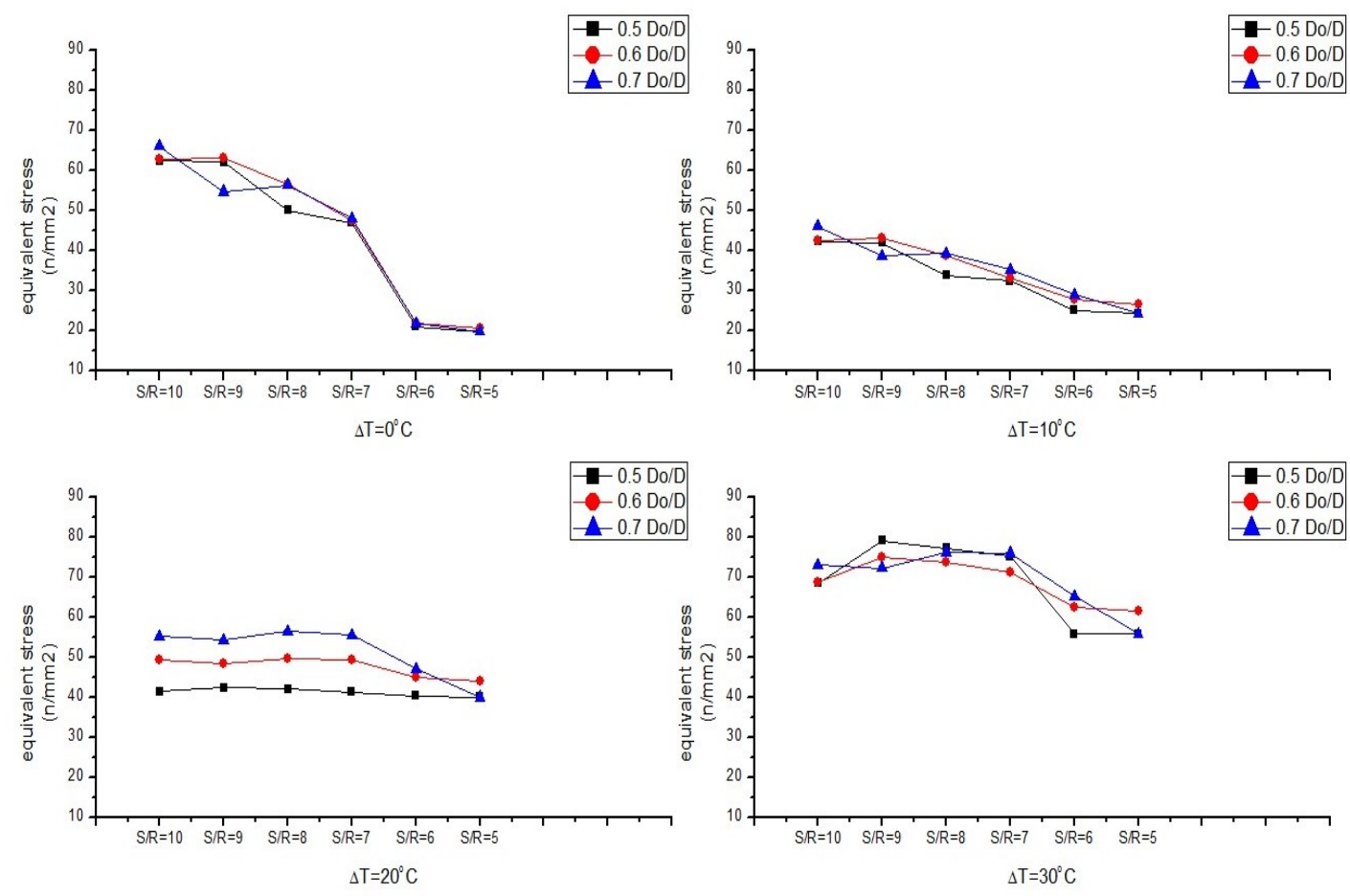

Figure 5 Equivalent stress in castellated girder for different $\mathrm{Span} / \mathrm{Rise}(\mathrm{S} / \mathrm{R})$ ratio at variable temperature for hinge support condition 

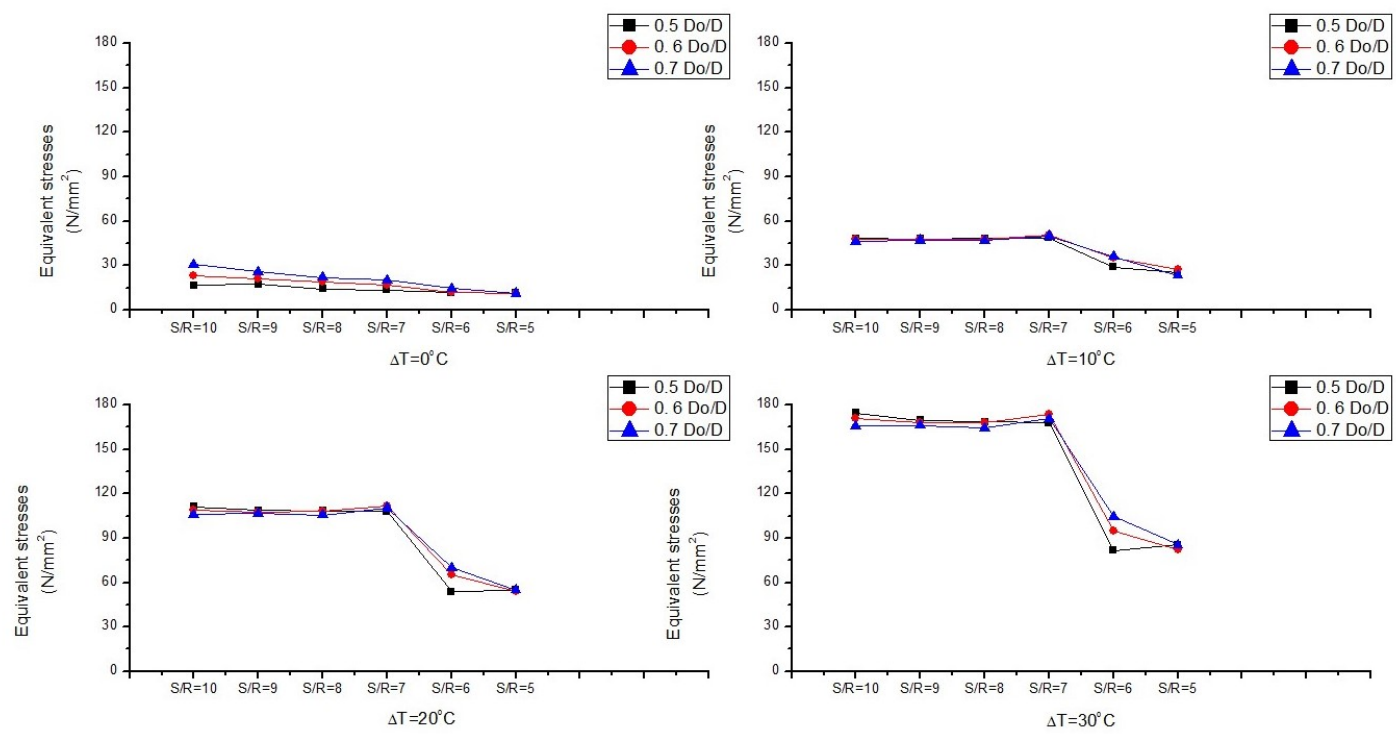

Figure 6 Equivalent stress in castellated girder for different Span/Rise (S/R) ratio at variable temperature for fixed support condition

\section{Results and discussion}

For conducting parametric study, the dimension of the opening is varied with respect to overall depth of the beam. In this case, a ratio of diameter of opening $\left(\mathrm{D}_{\mathrm{o}}\right)$ to depth $(\mathrm{D})$ is adopted as $0.5,0.6$ and 0.7 . In addition, the span $(\mathrm{S})$ to rise $(\mathrm{R})$ ratio of the circular arch is varied from ten to five. The arch beams are subjected to loading along with variation in temperature on its outer and inner sides. FE analysis of each girder is carried for a temperature variation of $0^{\circ} \mathrm{C}$ to $30^{\circ} \mathrm{C}$ at an interval of $10^{\circ} \mathrm{C}$. The effect of temperature variation in girder across the depth of the section is shown in fig. 4 . Equivalent stress in the member under variable temperature for hinged and fixed support condition is shown in fig. 5 and fig. 6 respectively. Maximum equivalent stress in the girder reduces by large value between $\mathrm{S} / \mathrm{R}$ ratio 7 and 6 . This shows that the lateral thrust generated in the arch comes into effect at $\mathrm{S} / \mathrm{R}$ ratio lesser than 6 . However, increasing the arch rise to $1 / 5^{\text {th }}$ of the span is very expensive process and hence not advisable. Also the fabrication process might lead into generation of additional stresses which needs to be accounted for during analysis and hence girder with $\mathrm{S} / \mathrm{R}$ ratio less than 6 cannot be recommended. For this ratio to be greater than 7 does not provide enough reduction in stresses that can be benefited in lieu of providing the arch profile. The reduction in stresses is maximum in case of $\mathrm{D}_{\mathrm{o}} / \mathrm{D}$ ratio of 0.5 which is reasonable as the web participation in resisting the flexural loading is maximum in this case as compared to other $\mathrm{D}_{\mathrm{o}} / \mathrm{D}$ ration of 0.6 and 0.7 . In case of hinged and fixed support condition, the stresses reduces by $25.92 \%$ and $51.24 \%$ as the $\mathrm{S} / \mathrm{R}$ ratio reduces from 7 to 6 when the variable temperature is maximum at $40^{\circ} \mathrm{C}$. The variation in temperature causes tensile stresses at the top. These stresses are counteracted by the normal thrust caused by arch action of the curved beam, which increases considerably in case of S/R ratio of 6 .

\subsection{Conclusion}

Finite Element analysis of a curved castellated girder is conducted in cases where the variation of temperature is caused due to internal functional requirement of the building and external 
environmental conditions. The parametric study for different span to rise ratio of the curved castellated girder has been conducted for different size of circular openings with respect to the overall depth of the beam. Following conclusions can be derived from the above study:

1. Under standard loading condition with thermal variation on two surfaces it is observed that the deflection of beam reduces with the decrease in span/rise ratio.

2. The reduction in equivalent stresses generated due to normal loading and temperature variation is less than $10 \%$ as $\mathrm{Span} /$ Rise ratio reduced from 10 to 7 . However, it reduces drastically up to $25.92 \%$ and $51.24 \%$ for hinged and fixed support conditions respectively as Span/Rise ratio reduced from 7 to 6 .

3. The above mentioned reduction shows that effective arch action is possible when span to rise ratio of the arch is equal to or less than 6.

4. As the opening/depth of the beam ratio increases, the deflection and stresses in the girder increases. This shows that the web plays an important role in reducing the internal stresses.

\section{References}

[1] A. Omar, T. K. steele. "Thermal deformations and stresses in circularly curved thin beams and rings." Journal of Thermal Stresses, 2007: 233-255.

[2] C. King, D. Brown. Design of curved steel. Design of curved steel, 2001.

[3] D. Darwin. Design of steel and composite beams with web openings. American Institute of Steel Construction, 1990.

[4] G. De Souza, R. Fakury, J. Carlos. "Design aids for unreinforced web openings in steel and composit beams with W-shapes." engineering journal, 2011: 1-14.

[5] K. D. Tsavdaridis, C. D'mello. "Web buckling study of the behaviour and strength of perforated steel beams with different novel web opening shapes." journal of constructional steel research, 2011: 1605-1620.

[6] K.F. Chung, C.H. Liu, A.C.H. Ko,. "Steel beams with large web openings of various shapes and sizes: an empirical design method using a generalized moment-shear interaction curve." Journal of Constructional Steel Research, 2003: 1177-1200.

[7] K.F. Chung, T.C.H. Liu, A.C.H. Ko. "Investigation on vierendeel mechanism in steel beams with circular web openings." journal of constructional steel research, 2001: 467-490.

[8] S. Darji. Impact of opening on failure mechanism of perforated steel beams. M.E. thesis, Vadodara: M.S. University, 2015.

[9] S. G. Morkhade,L. M. Gupta. "An experimental and parametric study on steel beams with web openings." International Journal of Advanced Structural Engineering, 2015: 249-260.

[10] S. G. Morkhade,L. M. Gupta. "Analysis of steel i-beams with rectangular web openings: experimental and finite element investigation." engineering structures and technologies, 2015: 13-23.

[11] S. G. Morkhade,L. M. Gupta. "Experimental study and rotational capacity of steel beams with web openings." International journal of civil and structural engineering, 2015: 58.

[12] T.C.H. Liu, K.F. Chung. "Steel beams with large web openings of various shapes and sizes: finite element investigation." journal of constructional steel research, 2003: 1159-1176.

[13] W. Zaaroue, R. Redwood. "Web buckling in thin webbed castellated beams." journal of structural engineering, 1996: 860-866.

[14] Y. L. Pi, M. A. Bradford. "In-plane strength and design of fixed steel I-section arches." Engineering Structures, 2004: 291-301. 